BMJ Open Ophthalmology

\title{
Structure of the lens and its associations with the visual quality
}

\author{
Xiaoting Ruan, Zhenzhen Liu (D) , Lixia Luo, Yizhi Liu
}

To cite: Ruan X, Liu Z, Luo L, et al. Structure of the lens and its associations with the visual quality. BMJ Open Ophthalmology 2020;5:e000459. doi:10.1136/ bmjophth-2020-000459

Received 22 February 2020 Revised 22 August 2020 Accepted 24 August 2020
Check for updates

\section{(c) Author(s) (or their} employer(s)) 2020. Re-use permitted under CC BY-NC. No commercial re-use. See rights and permissions. Published by BMJ.

State Key Laboratory of Ophthalmology, Sun YatSen University Zhongshan Ophthalmic Center, Guangzhou, China

Correspondence to Professor Zhenzhen Liu; liuzhenzhen@gzzoc.com and

Professor Lixia Luo; luolixia@ gzzoc.com

\section{ABSTRACT}

In humans, the lens is the organ with the ability to change morphology and refractive power, designated as accommodation, to focus light from various distances and obtain clear retinal image. The accommodative ability of the lens depends on its structure and biological parameters. The lens grows throughout the life, forming specific lens sutures and a unique gradient refractive index, and possesses regenerative ability under certain circumstances. Minimally invasive lens surgery that preserves endogenous lens epithelial stem/progenitor cells (LECs) can achieve functional lens regeneration in humans. The lens is the main source of intraocular aberration, especially intraocular higher-order aberrations (IHOAs) which is found to be binocularly symmetrical in phakic eyes. There is a compensation mechanism between corneal aberrations and lens aberrations. Therefore, the structure and the biological parameters of the lens, the binocular relationship of the lens and the correlation between the lens and cornea affect visual quality. This paper summarises the above findings and their current and potential applications in refractive surgeries, providing a comprehensive understanding of the lens as a strong determinant of visual quality in the optical system.

\section{INTRODUCTION}

The human eye is a dynamic, complex optical system. Accommodation, the mechanism by which an human eye increases refractive power, is produced by change in shape of the lens initiated by contraction of ciliary muscle. ${ }^{1}$ Accommodative ability of the lens allows us to see objects at different distances clearly. ${ }^{2}$ Accommodative ability of the lens is associated to its biological parameters. ${ }^{3}$ The lens grows throughout the life forming layer-by-layer structure, lens sutures and corresponding gradient refractive index (GRIN); therefore, its biological parameters are constantly changing with age. ${ }^{4}$ There is a balance between corneal positive spherical aberration and lens negative spherical aberration in young people. ${ }^{5}$ Understanding the lens and its role in accommodation and optimising visual quality is important in developing solutions when the lens is affected by ageing or disease.

\section{THE STRUCTURE OF THE LENS DEFINES ITS PHYSIOLOGICAL FUNCTION \\ The anatomy and physiological function of the lens}

The lens is an epithelial differentiated organ, which is elastic and transparent with a biconvex shape. It is located in the posterior chamber and supported by the vitreous body (figure 1A,B).

The lens consists of four parts (figure 1C): the lens capsule, the epithelial cells, the lens fibres and the zonules. Under normal circumstances, the lens is suspended on the ciliary body by the lens zonules, which are attached between the pars plana and the equatorial lens capsule.

The transparency of the lens allows light transmission with wavelengths up to 1200 nm. ${ }^{6}$ The prerequisites to maintain lens transparency include the tight and orderly arrangement of the lens fibre and the high solubility of lens proteins. ${ }^{7}$

The lens has the ability to accommodate to obtain clear retinal images of objects at different distances. Accommodation is accomplished by both the lens and the ciliary body. ${ }^{8}$ According to the Helmholtz accommodation theory, when looking at the distant objects, the ciliary muscles relax, so the lens zonules are in tension and the lens becomes flattened. On the other hand, for clear near vision, the ciliary muscle contracts and the lens zonules are relaxed, leading to the increasing convexity of the lens ${ }^{9}$ (figure 2 and online supplemental video).

Dynamic changes of the physiological function of the lens: refraction and accommodation

The epithelial cells in the equatorial part of the lens continue to differentiation and grow throughout life, so the shape, weight and volume of the lens are constantly changing. The diameter of adult lens is about 9.0$10.0 \mathrm{~mm}$, with an average annual growth of $0.023 \mathrm{~mm}$ and a thickness of lens is about $4.0-5.0 \mathrm{~mm} .{ }^{10}$ Using different devices, many 


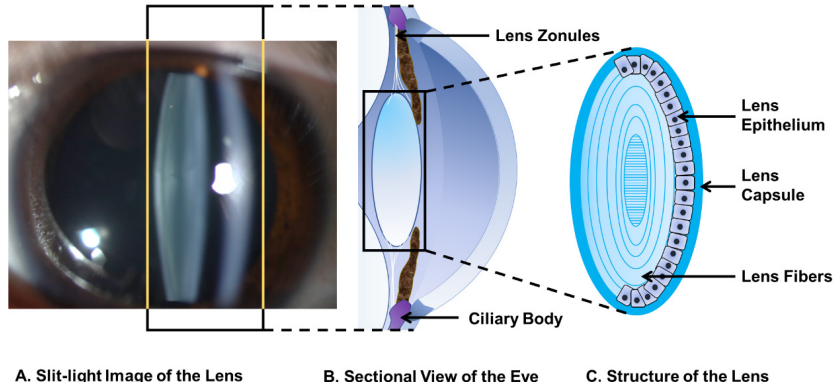

Figure 1 Slit-lamp microphotography and diagram of the structure of the lens. (A) Slit-lamp microphotography of the eye after mydriasis. The biconvex shape of the lens is clearly seen. (B) The diagram of the sectional view of the square part in the Panel A. (C) The cellular structure of the lens.

studies found that the anterior and posterior radius of curvature of the lens decreased significantly with age. Anterior segment optical coherence tomography (ASOCT) and Scheimpflug imaging can provide sectional view of the ocular anterior segment including the lens. Dubbelman et al used Scheimpflug imaging technology to measure the radius of anterior lens surface curvature (RAL) and found that the RAL decreases $57 \mu \mathrm{m}$ per year, and the radius of curvature of the posterior lens decreases $17 \mu \mathrm{m}$ per year. ${ }^{11}$ Liu et al assessed the RAL measurements using AS-OCT and Scheimpflug imaging, RAL is found to decrease with age ${ }^{12}$ Rosen et al measured the lens biological parameters of isolated eyes with different ages (20-99 years old) and found that the anterior curvature and thickness of the lens increased with age, but the posterior surface curvature of the lens changed little. ${ }^{13}$ However, the lenses are not held under force and the younger lenses will be in an accommodated form in in-vitro studies. Therefore, the research results cannot fully reflect the state of lens in vivo.

\section{Dynamic change of the lens refractive power}

The mean lens power in newborns is $45 \mathrm{D}$, and it decreases to $25 \mathrm{D}$ at the age of 6 years. ${ }^{14}$ In Gullstrand model eyes, the refractive index of the lens cortex and nucleus are defined as 1.386 and 1.406 , respectively. ${ }^{15}$ In fact, the lens has a more complex GRIN. ${ }^{16}$ Jones et al confirmed GRIN by using magnetic resonance imaging (MRI) to measure the sagittal refractive index distribution and age changes of human lens. ${ }^{17}$ Their results showed that the refractive

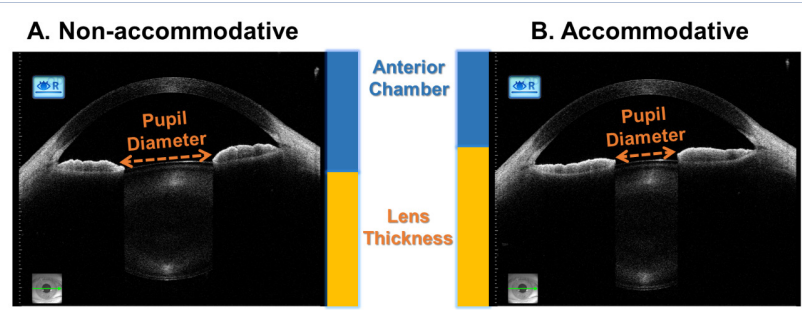

Figure 2 Diagram of the morphological and parametric changes of the lens during accommodation. index of the lens nucleus decreased significantly with age, while the refractive index of the lens cortex remained unchanged. The results show that with the increase of age, the overall refractive index of the lens decreases, resulting in decrease of the lens refractive power.

\section{Accommodation and its age-related change}

The accommodation ability of the lens greatly depends on its flexible surface curvature. The lens morphology and GRIN change with age and in the process of accommodation. ${ }^{1819}$ The RAL decreases and the lens refractive power increases during accommodation. ${ }^{20} 21$ Kasthurirangan et al used MRI technique to observe the changes of the lens and the ciliary muscle in vivo of different ages under the accommodative stimulation of -4.8 to $-6.9 \mathrm{D}$. $^{22}$ The results showed that the anterior chamber became shallower, the RAL decreased, the diameter of the equatorial part of the lens decreased and the diameter of the ciliary ring decreased. With the increase of age, the thickness of the lens and the equatorial diameter of the lens increased, but the radius of curvature of the posterior lens of the lens did not change. Furukawa et al recorded the dynamic process of the eye from accommodation to relaxation using the self-developed AS-OCT. ${ }^{23}$ When the lens is in the accommodation state, the anterior chamber becomes shallower, the lens thickness increases, and the radius of curvature of the anterior and posterior surface becomes smaller. Ni et al compared the changes of lens in the young group and presbyopia group under accommodation stimulation with a Scheimpflug camera. ${ }^{24}$ In the young subjects, the RAL significantly decreased and the lens thickness increased at $-5 \mathrm{D}$ accommodation stimulation. However, there was no significant change in lens parameters in the presbyopia group. Some studies have shown that under accommodation stimulation, the lens nucleus becomes more convex, the central thickness increases, while the equatorial diameter decreases. ${ }^{25}$ Some studies have shown that GRIN changes little during lens accommodation. ${ }^{26-28}$ Generally, the above studies showed that with the increase of age, the accommodative latency gradually increased, and the overall biomechanics of the lens was not affected by age.

\section{The embryonic development and specific suture formation of} the lens

The growth of crystalline lens can be divided into two stages (figure 3): the formation of lens vesicles and the production of lens fibers. ${ }^{29}$ At the 22nd day of the embryo, the neural folds on both sides of the forebrain developed from the neural tube invaginate, forming the optic groove, which continues to form optic vesicle. The distal end of the optic vesicle continues to expand and form a double-layer cup-shaped structure, called the optic cup. After contact with the epidermal ectoderm, the optic vesicle induces thicken of epidermal ectoderm to form a lens placode, which is the primordium of the lens. The lens placode gradually detaches from the epidermal ectoderm to form lens vesicles. ${ }^{30}$ 


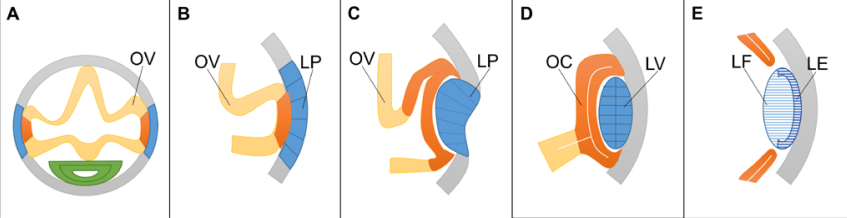

Figure 3 Embryonic development of the lens. (A)

Transverse section of a neural tube-stage embryo where the OV reaches the epidermal ectoderm. (B) After contact with the epidermal ectoderm, the optic vesicle induces thicken of epidermal ectoderm to form LP, which is the primordium of the lens. (C) LP thickens and invaginates. (D) The distal end of the optic vesicle continues to expand and form a doublelayer cup-shaped structure, called the OC. Lens placode separates from the head ectoderm to form the LV. (E) The anterior parietal cells of lens vesicles differentiated into LE, while the posterior cells gradually elongated to form primary LF. LE, lens epithelium; LF, lens fibres; LP, lens placode; LV, lens vesicle; OC, optic cup; OV, optic vesicle.

The anterior parietal cells of lens vesicles differentiated into lens epithelium, while the posterior cells gradually elongated to form primary lens fibres (figure $4 \mathrm{~A}$ ). The epithelial cells in the equatorial region of the lens continue to proliferate and grow, forming secondary lens fibers. ${ }^{31}$ The newly formed fibres surround the inner layer of fibres forming an onion-like structure. This process lasts for a lifetime but slows down with age. The ends of the fibres in each layer flatten and combine with each other to form a lens suture, with a Y-shaped suture in front of the nucleus and an offset Y-suture behind the nucleus (figure 5).

The highly organised arrangement and intercell connection with cellular gap junctions are crucial for
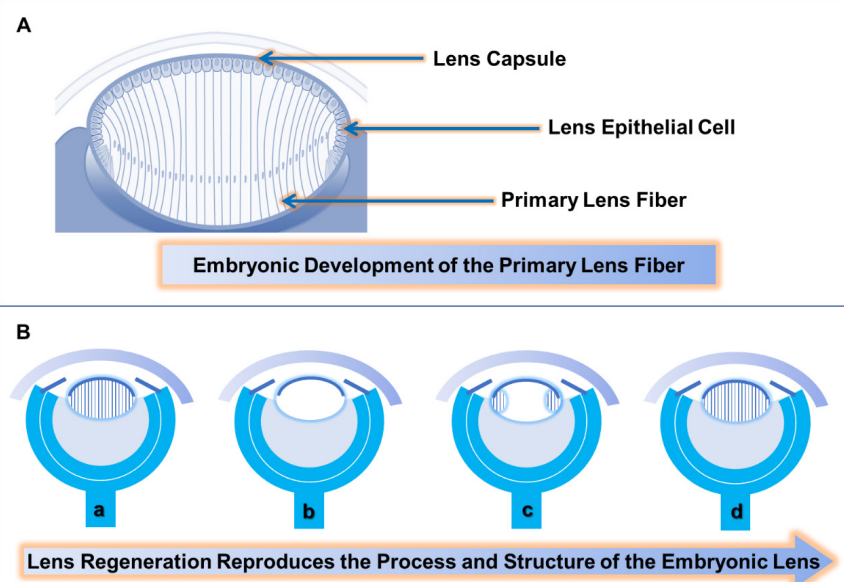

Figure 4 Lens regeneration in human may reproduce the normal structure of the lens. (A) Embryonic development of the primary lens fibres. ( $B$ Lens regeneration reproduces the process and structure of the embryonic lens. (a) A natural crystalline lens. (b) The lens content is removed and the lens capsule and the lens epithelium are preserved. (c) The regenerated lens fibres grow from the periphery to the centre. (d) The regenerated lens fibres elongate and refill the lens capsule.
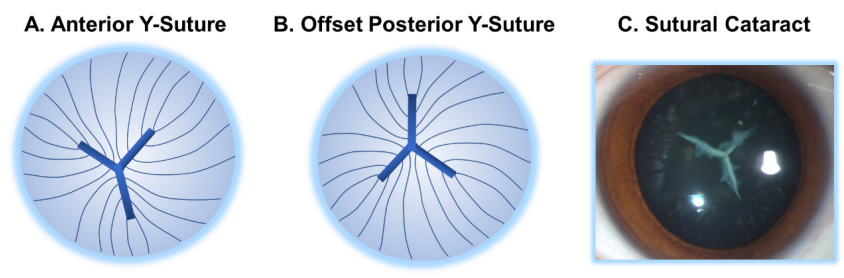

Figure 5 Anterior Y-suture and offset posterior Y-suture in humans. (A) The anterior ends of lens fibres are paired to form the Y-suture. (B) The posterior ends of lens fibres are paired to form an offset posterior Y-suture. (C) Sutural cataract is a morphological category of congenital cataract. The opacity located at the Y-suture makes the Y-shape clearly visible.

maintenance of lens transparency. ${ }^{32}$ The solubility of intracellular high concentration of crystalline also greatly reduces light scattering. ${ }^{33-35}$ In the human embryonic stage, orderly arrangement and polarised growth begin to appear only when the secondary lens fibres appear, forming a growth layer, which marks the formation of lens suture. ${ }^{36}$ After birth, the suture of the human lens tends to be complicated and star-shaped sutures appear. Lens suture is the tissue structure principally responsible for lens aberration, such as astigmatism, spherical aberration, trefoil and so on, and the direction of lens suture is related to the axis of non-rotational symmetric aberration. ${ }^{37}$ Lens suture also plays an important role in accommodation. ${ }^{38}$ Kuszak et al found that accommodative ability of the lens is related to quantitative differences in fibre structure and suture organisation. ${ }^{39}$ For example, compared with birds, human lenses with surface discontinuous sutures have weaker accommodative ability.

\section{Structure and function of the regenerated lens}

Mammalian lens derives from the embryonic epithelial ectoderm which possesses the potential to regenerate after trauma or surgery. It has been found that if only the contents of the lens are removed and the lens capsule is preserved, the residual lens epithelial cells (LECs) can proliferate and regenerate lens materials. ${ }^{40-42}$ Lin et al removed the lens contents in New Zealand albino rabbits. On the seventh day after operation, the LECs on the posterior capsule elongated, changed from cubic to columnar and came into direct contact with the LECs under the anterior capsule, and the eosinophilic substance between the anterior and posterior capsule disappeared. This process reproduces the formation of primary lens fibres during embryonic development (figure 4B). However, researchers found that compared with natural lenses, the epithelial cells of the regenerated lenses had some morphological changes, including overly dense, indented nuclei, some oedematous mitochondria and an expanding endoplasmic reticulum. ${ }^{43}$

The optical quality of regenerated lens depends on its transparency, shape and elasticity, refractive power and aberrations. Some studies give qualitative statements. In 
the eyes of the rabbits that did not receive the implants, Gwon showed a picture of the fundus clearly visible. ${ }^{44} \mathrm{Lin}$ et al studied lens regeneration in the New Zealand albino rabbits and found that the average refractive power of the regenerated lens was $15.6 \mathrm{D}$ at 15 th month after operation, which was similar to that of the normal lens. ${ }^{42}$ Lin et al also analysed the function of the regenerated lens with a randomised clinical trial in 12 human cataractous infants receiving minimally invasive lens surgery versus 25 cataractous infants receiving traditional cataract surgery as control. It was found that the refractive power of the regenerated lens increased significantly from 1 week to 8 months after the operation and reached approximately $80 \%$ of that of the same age at 8 months after minimally invasive lens surgery. At the same time, the average accommodative response of the regenerated lens increased to $2.5 \mathrm{D}$, which was much higher than that of the control group $(\mathrm{p}<0.001)$.

\section{THE ROLE OF THE LENS IN VISUAL QUALITY}

\section{Effects of the lens on retinal imaging}

The ocular aberration refers to the position deviation between the ideal wavefront shape and the actual wavefront shape. Light is a travelling electromagnetic wave. When travelling through a medium, the surface formed by light emitting at the same time is define as wavefront. For an aberration-free eye, the infinitely distant point light source enters the eye through different areas of the pupil and focuses on the same point on the retina. However, in an aberrated eye, the point source does not focus on the same point on the retina and the retinal image of the point light source is hazy (figure 6).

Ocular aberrations include low-order aberrations and high-order aberrations, in which low-order aberrations refer to defocus and astigmatism, and high-order

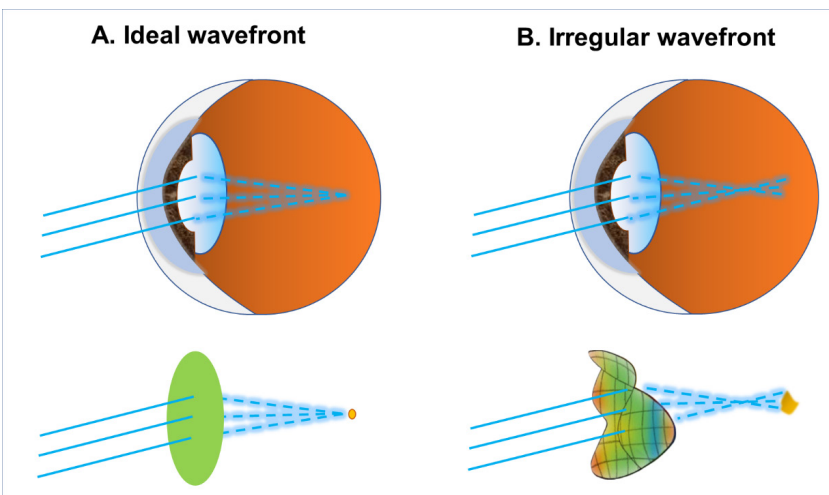

Figure 6 Diagram demonstrating the effects of irregular wavefront on the quality of retinal imaging. Light is a travelling electromagnetic wave. When travelling through a medium, the surface formed by light emitting at the same time is define as wavefront. (A) The infinitely distant point light source enters the optically ideal eye, which has a flat wavefront, and forms a clear point image on the retina. (B) The infinitely distant point light source enters the eye with aberrations, which has a distorted wavefront, and forms a hazy irregular image on the retina. aberrations include spherical aberration, coma, trefoil and so on. The low-order aberration accounts for a large proportion in human eye aberration, but it can be well corrected with glasses. Therefore, higher-order aberrations have become an important index to evaluate the visual quality after refractive surgery. The high-order aberrations of human eyes mainly come from the cornea and the lens, including spherical aberration and coma (including vertical and horizontal coma aberration). Previous studies have shown that the higher-order aberrations of the eyes increase with age, mainly due to changes in the lens. ${ }^{456}$ Under the condition of $6 \mathrm{~mm}$ pupil diameters, the intraocular spherical aberration $\left(\mathrm{Z}_{4}^{0}\right)$ was positively correlated with age $(\mathrm{r}=0.382, \mathrm{p}<0.001)$, and the intraocular coma aberration $\left(\mathrm{Z}_{4}{ }^{1}\right)$ was negatively correlated with age $(r=0.459, \mathrm{p}<0.001)$.

The age-related increase in lens-derived ocular aberrations results in decline of the modulation transfer function (MTF). Generally, the contrast of output image through an optical system is worse than that of input image. This variation of the contrast is closely related to the spatial frequency characteristics. The ratio of contrast between output image and input image is defined as MTF. Because the contrast of the output image is always less than that of the input image, the MTF value is between 0 and 1 . MTF showed a turning point and decreased at the age of 40 years ${ }^{47}$

The higher-order aberrations of the lens also changed during the accommodation process. ${ }^{48}$ The results of Ke $e t$ $a l$ showed that higher-order aberrations change in gradually increased accommodation stimulus: $\mathrm{Z}_{4}^{0}$ decreases during -2D stimulation, and $\mathrm{Z}_{3}^{-1}, \mathrm{Z}_{3}{ }^{1}, \mathrm{Z}_{4}^{0}, \mathrm{Z}_{6}^{0}$ become negative during $-4 \mathrm{D}$ stimulation and the negative change of $\mathrm{Z}_{3}{ }^{1}$ is related to the change of anterior curvature of the lens during accommodation. ${ }^{49}$ Visual experience is considered to play an important role in regulating the axial growth of the eye, and humans also show transient changes in axial and choroidal thickness after shortterm defocus exposure. Lau et alstudied the relationship between high-order aberrations and axial growth in children in Hong Kong. ${ }^{50}$ The results showed that the total high-order aberrations and spherical aberration (the combination of $\mathrm{Z}_{4}^{0}$ and $\mathrm{Z}_{6}{ }^{0}$ ) had a negative correlation with axial elongation, supporting the potential role of higher-order aberrations, including those from the lens, in childhood eye growth. Intraocular higher-order aberrations were mainly affected by the lens biological parameters. Zhang et al found similar results in children and young adults. ${ }^{51}$

\section{Mutual compensation of ocular aberrations originated from cornea and the lens}

It is found that in most young people, the corneal aberration alone is larger than the whole eye aberration, and there is mutual compensation between corneal and lens aberrations; the positive spherical aberration of the cornea can be compensated by the negative spherical aberration of the lens to maintain the balance of 
the overall aberration of the human eye to obtain better retinal imaging quality. ${ }^{52}$ In addition, asymmetric corneal aberrations, such as corneal astigmatism, can also be compensated by the lens, while corneal coma and lens aberrations mutually compensate to maintain the balance of ocular total aberrations. Corneal horizontal coma compensation varies with the amount of optical decentration. In patients with large Kappa angle, horizontal coma compensation is more obvious, which is common in hyperopia. ${ }^{53}$ The compensation effect of aberration decreases with the increase of age. In the elderly, the compensation effect of lens on corneal aberration obviously weakened or even disappeared. ${ }^{54}$

\section{Effects of binocular symmetry of the lens on ocular aberrations}

The symmetry of binocular optical system is the structural basis of the symmetry of binocular vision and aberration, which contribute to binocular depth perception and stereopsis. ${ }^{55}$ The symmetry of binocular optical system is reflected in the following aspects: (1) the corneal parameters of both eyes were highly symmetrical: there was a strong correlation among corneal thickness $(\mathrm{R}=0.90$, $\mathrm{p}<0.001)$, corneal curvature $(\mathrm{R}=0.95, \mathrm{p}<0.001)$ and posterior corneal surface height $(\mathrm{R}=0.72, \mathrm{p}<0.001) .{ }^{56}$ (2) the lens parameters of both eyes were highly symmetrical: Wang et al found that there is a mirror symmetry relationship between the tilt size and direction of the binocular lens. ${ }^{57}$ The results of $\mathrm{Li}$ et al show that there is a symmetry in the thickness of the binocular lens. ${ }^{58}$

To define the normal range of binocular symmetry of each biological parameter of lens has important clinical opinion for guiding the parameter setting of refractive surgery.

\section{FUTURE DIRECTIONS FOR OCULAR REFRACTIVE SURGERIES INVOLVING THE LENS}

It is difficult to fully restore the physiological function of the lens by using intraocular lens replacement therapy, as the function of the lens, especially accommodation, greatly depends on the cooperation of various components including the lens material, the lens capsule, the zonules and the ciliary muscles. Lin et al have established a novel surgical strategy for infantile cataract designated as minimally invasive lens-content-removal surgery (MILS) for lens regeneration (figure 7). ${ }^{42}$ The $1-1.5 \mathrm{~mm}$ capsulorhexis opening located in the periphery of the anterior capsule of the lens is beneficial

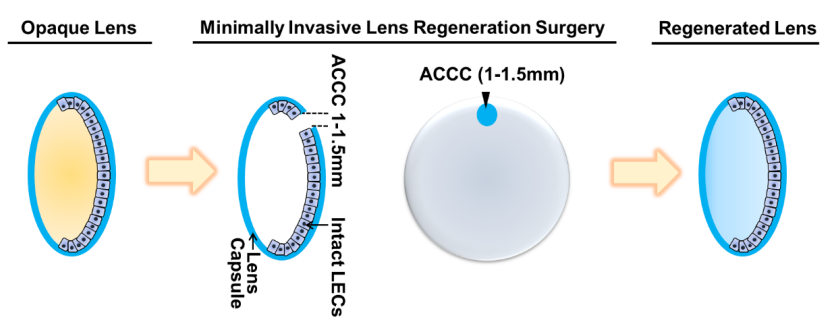

Figure 7 Diagram of minimally invasive lens surgery. to the contraction and closure of the capsulorhexis opening in the early postoperative period and to reduce its influence on the shape of the regenerated lens. In this way, functional lens regeneration originated from the endogenous lens stem cells in 12 children with bilateral congenital cataract can be observed. The MILS provides a new strategy for the reconstruction of lens function. The advantages of the MILS lie in using the proliferation and differentiation ability of the endogenous lens cells to obtain orderly arrangement of lens fibres and transparent lens regeneration in situ.

However, the MILS is currently only applicable to infants and young children. Regenerative capacity of LECs in human adults is insufficient. ${ }^{59}$ Using Bromodeoxyuridine (BrdU) labelling, Lin et al found that the number of proliferative cells located at donor eyes' lens capsule decreases with age. ${ }^{42}$ So, it is difficult to achieve orderly and transparent regeneration after lens removal in adults. In addition, the biological characteristics of accommodative components outside the lens vary with age and may impact the ability of the eye to accommodate. While Richdale et al reported that the intensity of ciliary muscle contraction induced by per dioptre stimulation is not related to age, Krag et al reported that the mechanical properties of lens capsule changes with age, resulting in decrease of lens flexibility ${ }^{60-62}$ How to extend the indications of the MILS surgery to a wider age range warrants extensive basic and clinical research. We need to know about the quantitative changes in biological parameters of the lens and in biomechanical properties of the extralenticular part of the accommodative apparatus with age, so as to provide reference for the intervention or manipulation needed when using the MILS in different age groups of adults. With the rapid development in swept source AS-OCT, three-dimensional image reconstruction technology and algorithms in artificial intelligence, it is possible to build an age-based theoretical model reflecting the main physiological characteristics of the lens and the accommodation process.

Correction notice This article has been corrected since it was published. The title and level of section headings have been updated as per journal style.

Contributors XR and ZL wrote the first draft of the paper. ZL added clinical content and figures. YL and LL critically reviewed this draft. $\mathrm{ZL}$ and $\mathrm{LL}$ are the corresponding authors. All authors take responsibility for the content.

Funding This study was supported by the National Natural Science Foundation of China $(81873675,81770905)$ and the Construction Project of High-Level Hospitals in Guangdong Province (303020102).

Competing interests None declared.

Patient consent for publication Not required.

Provenance and peer review Not commissioned; externally peer reviewed.

Open access This is an open access article distributed in accordance with the Creative Commons Attribution Non Commercial (CC BY-NC 4.0) license, which permits others to distribute, remix, adapt, build upon this work noncommercially, and license their derivative works on different terms, provided the original work is properly cited, appropriate credit is given, any changes made indicated, and the use is non-commercial. See: http://creativecommons.org/ licenses/by-nc/4.0/. 


\section{REFERENCES}

1 Wagner S, Zrenner E, Strasser T. Emmetropes and myopes differ little in their accommodation dynamics but strongly in their ciliary muscle morphology. Vision Res 2019;163:42-51.

2 de Jong PTVM. The quest for the human ocular accommodation mechanism. Acta Ophthalmol 2020;98:98-104.

3 Yuan Y, Shao Y, Tao A, et al. Ocular anterior segment biometry and high-order wavefront aberrations during accommodation. Invest Ophthalmol Vis Sci 2013;54:7028-37.

4 Iribarren R. Crystalline lens and refractive development. Prog Retin Eye Res 2015;47:86-106.

5 Tabernero J, Benito A, Alcón E, et al. Mechanism of compensation of aberrations in the human eye. J Opt Soc Am A Opt Image Sci Vis 2007;24:3274-83.

6 Artigas JM, Felipe A, Navea A, et al. Spectral transmission of the human crystalline lens in adult and elderly persons: color and total transmission of visible light. Invest Ophthalmol Vis Sci 2012;53:4076-84.

7 Hejtmancik JF, Shiels A. Overview of the lens. Prog Mol Biol Trans/ Sci 2015;134:119-27.

8 Harper DG. Bringing accommodation into focus: the several discoveries of the ciliary muscle. JAMA Ophthalmol 2014;132:645-8.

9 Glasser A. Accommodation: mechanism and measurement. Ophthalmol Clin North Am 2006;19:1-12.

10 Dilmen G, Köktener A, Turhan NO, et al. Growth of the fetal lens and orbit. Int J Gynaecol Obstet 2002;76:267-71.

11 Dubbelman M, Van der Heijde GL. The shape of the aging human lens: curvature, equivalent refractive index and the lens paradox. Vision Res 2001;41:1867-77.

12 Liu Z, Ruan X, Wang W, et al. Comparison of radius of anterior lens surface curvature measurements in vivo using the anterior segment optical coherence tomography and Scheimpflug imaging. Ann Trans/ Med 2020;8:177.

13 Rosen AM, Denham DB, Fernandez V, et al. In vitro dimensions and curvatures of human lenses. Vision Res 2006;46:1002-9.

14 Tideman JWL, Polling JR, Jaddoe VWV, et al. Growth in foetal life, infancy, and early childhood and the association with ocular biometry. Ophthalmic Physiol Opt 2019;39:245-52.

15 Rassow B. [A model of Gullstrand's "normal eye"]. Ophthalmologica 1972;164:143-8.

16 Donaldson PJ, Grey AC, Maceo Heilman B, et al. The physiological optics of the lens. Prog Retin Eye Res 2017;56:e1-24.

17 Jones CE, Atchison DA, Meder R, et al. Refractive index distribution and optical properties of the isolated human lens measured using magnetic resonance imaging (MRI). Vision Res 2005;45:2352-66.

18 Shoji T, Kato N, Ishikawa S, et al. Association between axial length and in vivo human crystalline lens biometry during accommodation: a swept-source optical coherence tomography study. Jpn J Ophthalmol 2020;64:93-101.

19 Kasthurirangan S, Markwell EL, Atchison DA, et al. In vivo study of changes in refractive index distribution in the human crystalline lens with age and accommodation. Invest Ophthalmol Vis Sci 2008;49:2531-40.

20 Esteve-Taboada JJ, Domínguez-Vicent A, Monsálvez-Romín D, et al Non-invasive measurements of the dynamic changes in the ciliary muscle, crystalline lens morphology, and anterior chamber during accommodation with a high-resolution OCT. Graefes Arch Clin Exp Ophthalmol 2017;255:1385-94.

21 Augusteyn RC, Mohamed A, Nankivil D, et al. Age-dependence of the optomechanical responses of ex vivo human lenses from India and the USA, and the force required to produce these in a lens stretcher: the similarity to in vivo disaccommodation. Vision Res 2011;51:1667-78.

22 Kasthurirangan S, Markwell EL, Atchison DA, et al. MRI study of the changes in crystalline lens shape with accommodation and aging in humans. J Vis 2011;11. doi:10.1167/11.3.19. [Epub ahead of print: 25 Mar 2011].

23 Furukawa $\mathrm{H}$, Hiro-Oka $\mathrm{H}$, Satoh $\mathrm{N}$, et al. Full-range imaging of eye accommodation by high-speed long-depth range optical frequency domain imaging. Biomed Opt Express 2010;1:1491-501.

$24 \mathrm{Ni}$ Y, Liu X-L, Wu M-X, et al. Objective evaluation of the changes in the crystalline lens during accommodation in young and presbyopic populations using Pentacam HR system. Int $J$ Ophthalmol 2011;4:611-5.

25 Hermans E, Dubbelman M, van der Heijde R, et al. The shape of the human lens nucleus with accommodation. J Vis 2007;7:16-10.

26 de Castro A, Birkenfeld J, Maceo B, et al. Influence of shape and gradient refractive index in the accommodative changes of spherical aberration in nonhuman primate crystalline lenses. Invest Ophthalmol Vis Sci 2013;54:6197-207.
27 Wang K, Venetsanos D, Wang J, et al. Gradient moduli lens models: how material properties and application of forces can affect deformation and distributions of stress. Sci Rep 2016;6:31171.

28 Maceo BM, Manns F, Borja D, et al. Contribution of the crystalline lens gradient refractive index to the accommodation amplitude in non-human primates: in vitro studies. J Vis 2011;11:23.

29 Kumar B, Reilly MA. The development, growth, and regeneration of the crystalline lens: a review. Curr Eye Res 2020;45:1-14.

30 Shirai K, Tanaka S-I, Lovicu FJ, et al. The murine lens: a model to investigate in vivo epithelial-mesenchymal transition. Dev Dyn 2018;247:340-5

31 Cvekl A, McGreal R, Liu W. Lens development and crystallin gene expression. Prog Mol Biol Trans/ Sci 2015;134:129-67.

32 Shi W, Riquelme MA, Gu S, et al. Connexin hemichannels mediate glutathione transport and protect lens fiber cells from oxidative stress. J Cell Sci 2018;131. doi:10.1242/jcs.212506. [Epub ahead of print: 21 Mar 2018].

33 Liu Y, Zhang X, Luo L, et al. A novel alphaB-crystallin mutation associated with autosomal dominant congenital lamellar cataract. Invest Ophthalmol Vis Sci 2006;47:1069-75.

34 Liu Z, Taylor A, Liu Y, et al. Enhancement of ubiquitin conjugation activity reduces intracellular aggregation of V76D mutant $\gamma D$ crystallin. Invest Ophthalmol Vis Sci 2012;53:6655-65.

35 Liu Z, Wu M. [Comparison on molecular characteristics of human gamma D-crystallin protein and its five mutations]. Yan Ke Xue Bao 2007:23:129-35.

36 Fan J, Lerner J, Wyatt MK, et al. The klotho-related protein $\mathrm{KLPH}$ (Ictl) has preferred expression in lens and is essential for expression of clic5 and normal lens suture formation. Exp Eye Res 2018;169:111-21.

37 Gargallo A, Arines J, Acosta E. Lens aberrations and their relationship with lens sutures for species with Y-suture branches. J Biomed Opt 2013;18:25003.

38 Banh A, Bantseev V, Choh V, et al. The lens of the eye as a focusing device and its response to stress. Prog Retin Eye Res 2006;25:189-206.

39 Kuszak JR, Mazurkiewicz M, Jison L, et al. Quantitative analysis of animal model lens anatomy: accommodative range is related to fiber structure and organization. Vet Ophthalmol 2006;9:266-80.

40 Gwon A, Gruber LJ, Mantras C. Restoring lens capsule integrity enhances lens regeneration in New Zealand albino rabbits and cats. $J$ Cataract Refract Surg 1993;19:735-46.

41 Gwon A, Gruber L, Mantras C, et al. Lens regeneration in New Zealand albino rabbits after endocapsular cataract extraction. Invest Ophthalmol Vis Sci 1993;34:2124-9.

42 Lin $\mathrm{H}$, Ouyang $\mathrm{H}$, Zhu J, et al. Lens regeneration using endogenous stem cells with gain of visual function. Nature 2016;531:323-8.

43 Liu X, Zhang M, Liu Y, et al. Proteomic analysis of regenerated rabbit lenses reveal crystallin expression characteristic of adult rabbits. $\mathrm{Mol}$ Vis 2008;14:2404-12.

44 Gwon A, Kuszak J, Gruber LJ. Intralenticular implant study in pigmented rabbits: opacity lensmeter assessment. J Cataract Refract Surg 1999;25:268-77.

45 Li C, Zhang J, Yin X, et al. Distribution and related factors of corneal regularity and posterior corneal astigmatism in cataract patients. Clin Ophthalmol 2019;13:1341-52.

46 Rocha KM, Nosé W, Bottós K, et al. Higher-order aberrations of agerelated cataract. J Cataract Refract Surg 2007;33:1442-6.

47 Alió JL, Schimchak P, Negri HP, et al. Crystalline lens optical dysfunction through aging. Ophthalmology 2005;112:2022-9.

48 Nan L, Li L-hua, Tang X. [Progress of research in relationship between high order wavefront aberration and accommodation of human eye]. Zhonghua Yan Ke Za Zhi 2010;46:285-8.

$49 \mathrm{Ke} \mathrm{B}$, Mao X, Jiang $\mathrm{H}$, et al. The relationship between high-order aberration and anterior ocular biometry during accommodation in young healthy adults. Invest Ophthalmol Vis Sci 2017;58:5628-35.

50 Lau JK, Vincent SJ, Collins MJ, et al. Ocular higher-order aberrations and axial eye growth in young Hong Kong children. Sci Rep 2018;8:6726.

51 Zhang J, Jin G, Jin L, et al. Profiles of intraocular higher-order aberrations in healthy phakic eyes: prospective cross-sectional study. Ann Transl Med 2020;8:850.

$52 \mathrm{Li}$ XJ, Wang Y, Wu YN, XJ L, YN W, et al. [Distribution and compensation mechanism of aberrations between anterior and posterior surface of the cornea in myopia and myopic astigmatism eyes]. Zhonghua Yan Ke Za Zhi 2016;52:840-9.

$53 \mathrm{Lu} \mathrm{F,} \mathrm{Wu} \mathrm{J,} \mathrm{Shen} \mathrm{Y,} \mathrm{et} \mathrm{al.} \mathrm{On} \mathrm{the} \mathrm{compensation} \mathrm{of} \mathrm{horizontal}$ coma aberrations in young human eyes. Ophthalmic Physiol Opt 2008;28:277-82. 
54 Artal P, Guirao A, Berrio E, et al. Compensation of corneal aberrations by the internal optics in the human eye. $J$ Vis 2001;1:1-8.

55 Arba Mosquera S, Verma S. Bilateral symmetry in vision and influence of ocular surgical procedures on binocular vision: a topical review. J Optom 2016;9:219-30.

56 Myrowitz EH, Kouzis AC, O'Brien TP. High interocular corneal symmetry in average simulated keratometry, central corneal thickness, and posterior elevation. Optom Vis Sci 2005;82:428-31.

57 Wang L, Guimaraes de Souza R, Weikert MP, et al. Evaluation of crystalline lens and intraocular lens tilt using a swept-source optical coherence tomography biometer. J Cataract Refract Surg 2019:45:35-40.
$58 \mathrm{Li} \mathrm{Y,} \mathrm{Bao} \mathrm{FJ.} \mathrm{Interocular} \mathrm{symmetry} \mathrm{analysis} \mathrm{of} \mathrm{bilateral} \mathrm{eyes.} \mathrm{J} \mathrm{Med}$ Eng Technol 2014;38:179-87.

59 Stern JH, Tian Y, Funderburgh J, et al. Regenerating eye tissues to preserve and restore vision. Cell Stem Cell 2018;22:834-49.

60 Krag S, Danielsen CC, Andreassen TT. Thermal and mechanical stability of the lens capsule. Curr Eye Res 1998;17:470-7

61 Krag S, Olsen T, Andreassen TT. Biomechanical characteristics of the human anterior lens capsule in relation to age. Invest Ophthalmol Vis Sci 1997;38:357-63.

62 Krag S, Andreassen TT. Mechanical properties of the human posterior lens capsule. Invest Ophthalmol Vis Sci 2003;44:691-6. 